\title{
ESTRANGEIRISMOS DA INTERNET A FORÇA DE ATUAÇÃO DAS LAN HOUSES NO PROCESSO DE CRISTALIZAÇÃO DE EXPRESSÕES DO INGLÊS
}

\author{
Jhonatta Costa e Silva (UERJ e PUC-Rio) \\ jhoncostaffp@yahoo.com.br
}

\section{INTRODUÇÃO}

Com a grande revolução cibernética vivida pela sociedade global a partir da década de 1980, e com a intensificação desse movimento nos anos 90 e 00, o mundo foi apresentado a um novo vocabulário que, em pouco menos de duas décadas, tornou-se usual e constante na vida dos que, de alguma forma, vem no computador uma ferramenta. Ocorre que, por conta da origem norte-americana do advento da microcomputação no ocidente, os termos relacionados a essa área se apresentam em Inglês. Há raras exceções de países em que os termos se apresentam na língua materna, como Portugal, por exemplo, que utiliza a forma "rato" ao invés de "mouse" ou "sítio" no lugar de "site".

Dentro do universo da microcomputação, chama-nos atenção especial a internet. $\mathrm{O}$ crescimento progressivo e robusto do uso dessa ferramenta como meio de comunicação tanto em esfera interpessoal quanto mass media tem feito com que se ouçam expressões do tipo "você tá leg hoje, cara" ou "tá bugando, o PC tá bugando" (ambas retiradas de entrevistas feitas para este trabalho).

Torna ainda mais forte a presença da internet na fala cotidiana a solidificação do espaço das lan houses na sociedade urbana contemporânea. Como nem toda a população pode ter computador em casa, e com a evidência do discurso que apela para a inclusão digital, esses espaços próprios para o uso da rede virtual de informações seguem se consolidando como comunidades de prática, assunto que será desenvolvido mais detalhadamente no decorrer desta monografia. Se há dez anos as lan houses eram utilizadas apenas para pesquisas ou trabalhos práticos e rápidos, hoje são verdadeiros atrativos para crianças e adolescentes, por oferecerem acesso aos sites de relacio- 
namento (em alta nos últimos anos), aos serviços de mensagens instantâneas e aos jogos online.

Pretendemos avaliar a força de atuação das lan houses como comunidades de prática nos processos de aceitação dos anglicismos, bem como o raio de alcance de sua influência no macro espaço social em que se inserem. Para tanto, forma feitas vinte entrevistas, sendo 05 como falantes entre 10 e 14 anos de idade não frequentadores de lan houses, mas que possuem computador em casa, 05 com falantes entre 10 e 14 anos frequentadores de lan houses e que não possuem computador em casa, 05 como adultos entre 19 e 25 anos que, mesmo tendo computador em casa, possuem algum tipo de contato com as lan houses e 05 com falantes adultos acima de trinta anos que possuem pouquíssimo ou nenhum contato com o computador.

\section{Metodologia da pesquisa}

As entrevistas foram elaboradas, inicialmente, para cumprirem papel quantitativo. Perguntas mais gerais ficariam em segundo plano, sendo o alvo principal da pesquisa uma lista de vocábulos em Inglês utilizados diariamente por quem acessa a internet. $\mathrm{O}$ falante ouvia a lista de palavras e comentava uma por uma, e eram analisadas as descrições de cada item da lista. Num segundo momento, as mesmas palavras da lista eram inseridas em frases contextuais, e o falante comentava o enunciado a ele apresentado. Nesse momento, esperava-se que o contexto oferecido ratificasse ou retificasse a descrição dada anteriormente.

A comparação entre os grupos de falantes, entretanto, não poderia ser feita apenas de forma quantitativa. Era necessário um olhar mais atento para os dados, no sentido de achar os "porquês"daqueles resultados. Foi então que as outras perguntas, antes pensadas como atuantes em segundo plano, deram outros contornos aos dados coletados, e a pesquisa, idealizada para ser quantitativa, tornou-se também qualitativa. Os percentuais analisados foram alocados em tabelas comparativas, que aparecerão no corpo do trabalho, e as perguntas menos objetivas evidenciaram os motivos das discrepâncias entre as tabelas, a saber, a diferença etária e o hábito de frequentar ou não lan houses. 
Tudo isso serviu como subsídio para que se pudesse definir a lan house como, de fato, uma comunidade de prática, em que tanto se constrói uma identidade social de grupo quanto de indivíduo, como será abordado mais a frente.

\section{Algumas discussões sobre o tema}

Zilles, citada no presente trabalho por seu texto em parceria com Pedro Garcez (Cf. ZILLES e GARCEZ, 2001, p. 15-36.), continua a discussão sobre estrangeirismos no mesmo livro de Faraco, com o texto Ainda os equívocos no combate aos estrangeirismos. Ainda em parceria, Garcez e Zilles são úteis na discussão sobre estrangeirismos com o texto Estrangeirismos: empréstimo ou ameaça (Cf. GARCEZ e ZILLES, 2001, p. 39-52.)

\section{Fundamentos Teóricos}

Como base teórica, foram utilizados os textos:

"Além do repertório linguístico: aspectos simbólicos diversos na construção da identidade étnico-linguística alemã na escola de comunidade rural multilíngue", de Neiva Maria Jung e P. M. Garcez (Cf. JUNG e GARCEZ, 2007, p. 97-122) e "Estrangeirismos: desejos e ameaças", de A. M. S. Zilles e P. M. Garcez (ZILLES e GARCEZ, 2001, p. 15-36).

O texto de Jung e Garcez, apesar de tratar mais especificamente sobre políticas linguísticas, foi bastante útil por trazer a análise das relações entre indivíduos dentro do que se convencionou chamar de comunidade de prática, local em que as práticas em comum não se restringem ao modo de falar, formando uma gama de atividades que engendram o funcionamento dos hábitos do grupo. De fato, as lan houses são bons exemplos de comunidade de prática, já que seus participantes se reúnem com objetivos específicos e acabam por utilizar também linguagem específica.

Como o material da investigação é constituído de uma lista de estrangeirismos, foi necessário entender como funciona esse tipo de fenômeno linguístico, por que há tanto preconceito quando se fala 
nessa questão e de que forma os falantes tendem a aceitar ou renegar os vocábulos que vêm de fora. Nesse sentindo, foi de grande valia a leitura do texto de Zilles e Garcez, que colocam de maneira clara e comprovada o fato de que proibir o uso de termos estrangeiros é impossível se forem eleitos pelos próprios falantes.

\section{Breve panorama sobre os estrangeirismos}

O simples aparecimento de um termo de outra língua em um determinado idioma não pode ser classificado como estrangeirismo. Há termos que, por mais evidentes que estejam em uma comunidade de fala, não se cristalizaram no uso daqueles falantes. Haverá quem faça essa exata distinção entre estrangeirismo e empréstimo. Em nosso trabalho, consideraremos que estrangeirismos são palavras estrangeiras que, por conta do seu forte e constante uso em outra língua, acabam sendo depreendidas e usadas em larga escala pelos falantes daquela comunidade de fala. A grande questão é: como esses termos penetram numa determinada língua e que fatores decidem sua aceitação ou rejeição. Arcari e Colaço (2007) lembram que em um país como o Brasil, em que há abertura cultural considerável, os termos de outras línguas fatalmente penetrarão o vocabulário nacional, cedo ou tarde.

Nota-se que essa abertura para o estrangeiro é presente no Brasil, não só em termos linguísticos, mas principalmente em termos culturais. Em nosso século, o veículo ideológico é a indústria cultural, principalmente representada pelos meios de comunicação de massa, que contribuem para que o Brasil seja o mercado consumidor estrangeiro. (ARCARI \& COLAÇO, 2007, p. 11)

Em um país onde já não há tendência à rejeição do que vem de fora, os estrangeirismos acabam encontrando um lugar propício à sua propagação. Vejamos ainda o que dizem Garcez e Zilles sobre esse assunto:

Os elementos estrangeiros que surgem do contato linguístico muitas vezes têm vida curta, como as gírias, ou são incorporados de modo tão íntimo à língua que os acolhe, pelos processos normais de mudança linguística, que em duas gerações nem se quer são percebidos como estrangeiros (GARCEZ e ZILLES, 2001, p. 32) 
A grande questão acerca dos estrangeirismos gira em torno do preconceito. Há quem acredite que os termos estrangeiros podem dificultar a comunicação entre os falantes que desconhecem a língua de origem dos termos, e que só os que conhecem essa língua poderiam ter acesso à mensagem de um enunciado que porventura estivesse permeado de palavras estrangeiras. Vejamos ainda o que dizem Garcez e Zilles quanto a isso:

Um enunciado como "eu baixei um programa novo de computador" seria plenamente compreensível por todos os brasileiros de qualquer rincão. Mas isso não se passaria com o enunciado "eu fiz o download de um software novo" que seria incompreensível a qualquer brasileiro que não conhecesse Inglês, em função dos estrangeirismos. (GARCEZ e ZILLES, 2001, p. 32)

Mais adiante, com a apresentação dos dados coletados, veremos que há palavras oriundas da internet das quais o entrevistado desconhece o significado atribuído pelo dicionário, e que até mesmo desconhece a origem dessas palavras como da língua inglesa. É o caso de "site", "bug", dentre outras. Fato é que as palavras estrangeiras muito recorrentes dentro de situações de uso que são frequentes acabam por se incorporar naturalmente à lista de vocábulos ligada a essas situações.

\section{As lan houses}

As lan houses são espaços urbanos cada vez mais visitados, que nascem em um momento bastante oportuno, com a ampla divulgação pela mídia da inclusão digital. Inicialmente criadas com o propósito de servir àqueles que necessitavam da internet como ferramenta de pesquisa e não tinham condições de dispor de um computador em casa, foi, na verdade, com a moda dos jogos em rede e dos sites de relacionamento que esses espaços conquistaram sua força.

O objetivo principal deste trabalho é a obtenção de subsídios que possibilitem afirmar a força da comunidade de prática na construção do vocabulário dos falantes que a compõem. Antes, portanto, de apresentar os dados coletados, é necessário comentarmos um pouco o conceito de comunidade de prática, justificando-se a "lan hou$s e "$ como pertencente a esse grupo de espaços sociais. 
A noção de comunidade de prática permite abarcar a dinamicidade das relações sociais, atentando para o fato de que uma pessoa tanto pode adotar traços de um grupo (...) como pode resistir [a eles]." (ECKERT \& McCONNEL-GINET, 1992)

Como bem colocam as autoras supracitadas, numa comunidade de prática há a troca constante de traços identitários, tanto pela via falante $\rightarrow$ grupo quanto pela via grupo $\rightarrow$ falante. Assim, podemos perceber que a comunidade de prática é, ao mesmo tempo, construtora da identidade do falante e é por ele construída. De acordo com Etienne Wenger, Uma Comunidade de Prática designa um grupo de pessoas que se unem em torno de um mesmo tópico ou interesse. Essas pessoas trabalham juntas para achar meios de melhorar o que fazem, ou seja, na resolução de um problema na comunidade ou no aprendizado diário, através da interação regular. Dentro das lan houses, é comum ver o grupo bastante atento a qualquer possível dificuldade de alguém que, aparentemente, é um novo frequentador do local. Os adolescentes, em especial os meninos, são bastante solícitos e prestativos. De fato, para um iniciante nas práticas internas do grupo, como participar dos jogos em rede, pode requerer algum conhecimento de termos próprios (todos estrangeirismos) e a ajuda ao novato é indispensável.

Quando as lan houses abrem as portas para os jogos em rede e para os sites de relacionamento, há uma aceitação imediata da sociedade em relação a essas novidades, e isso ocasiona a formação de um público extremamente jovem. Com pouco tempo, a lan house perde o rótulo de "lugar para acesso à rede virtual de informações", adotando o de "lugar destinado ao público jovem".

A partir do momento em que esse acordo se ratifica e, de fato, as lan houses se configuram como lugares para jovens, os hábitos internos dessa comunidade dificilmente encontrarão nos mais velhos algum tipo de identificação. De acordo com os dados levantados, os falantes acima de trinta anos que não possuem internet em suas casas mostraram pouco ou nenhum conhecimento dos termos em Inglês utilizados na internet, como mostra a tabela a seguir:

\begin{tabular}{|l|l|l|}
\hline \multicolumn{3}{|c|}{ Falantes adultos que não possuem internet } \\
\hline & Descrição compatível & Aplicação na frase \\
\hline Download & $50 \%$ & $90 \%$ \\
\hline Link & $0 \%$ & $0 \%$ \\
\hline Web & $0 \%$ & $0 \%$ \\
\hline
\end{tabular}




\begin{tabular}{|l|l|l|}
\hline Home & $25 \%$ & $25 \%$ \\
\hline Homepage & $0 \%$ & $0 \%$ \\
\hline Scrap & $0 \%$ & $0 \%$ \\
\hline Scrapbook & $0 \%$ & $0 \%$ \\
\hline Bug & $0 \%$ & $0 \%$ \\
\hline Spam & $0 \%$ & $0 \%$ \\
\hline Send & $50 \%$ & $100 \%$ \\
\hline Print & $0 \%$ & $0 \%$ \\
\hline Password & $50 \%$ & $50 \%$ \\
\hline Profile & $0 \%$ & $0 \%$ \\
\hline Log in & $100 \%$ & $100 \%$ \\
\hline e-mail & $100 \%$ & $100 \%$ \\
\hline Site & $100 \%$ & $100 \%$ \\
\hline Messenger & $0 \%$ & $0 \%$ \\
\hline Network & $25 \%$ & $25 \%$ \\
\hline Pop up & $0 \%$ & $0 \%$ \\
\hline
\end{tabular}

Os dados coletados entre falantes acima de trinta anos que possuem internet em casa alcançaram expressão um pouco mais significativa, apensar de baixa, quanto à definição de termos da lista, o que se pode observar na seguinte tabela:

\begin{tabular}{|l|l|l|}
\hline \multicolumn{2}{|c|}{ Falantes adultos que possuem } \\
\hline & Descrição compatível & Aplicação na frase \\
\hline Download & $50 \%$ & $50 \%$ \\
\hline Link & $0 \%$ & $0 \%$ \\
\hline Web & $0 \%$ & $0 \%$ \\
\hline Home & $25 \%$ & $25 \%$ \\
\hline Homepage & $50 \%$ & $50 \%$ \\
\hline Scrap & $0 \%$ & $0 \%$ \\
\hline Scrapbook & $0 \%$ & $0 \%$ \\
\hline Bug & $0 \%$ & $0 \%$ \\
\hline Spam & $0 \%$ & $0 \%$ \\
\hline Send & $50 \%$ & $100 \%$ \\
\hline Print & $0 \%$ & $0 \%$ \\
\hline Password & $50 \%$ & $50 \%$ \\
\hline Profile & $0 \%$ & $0 \%$ \\
\hline Log in & $100 \%$ & $100 \%$ \\
\hline e-mail & $100 \%$ & $100 \%$ \\
\hline Site & $100 \%$ & $100 \%$ \\
\hline Messenger & $50 \%$ & $75 \%$ \\
\hline Network & $25 \%$ & $25 \%$ \\
\hline Pop up & $50 \%$ & $50 \%$ \\
\hline
\end{tabular}

A primeira constatação em relação ao fator faixa etária como sendo de forte influência na aceitação dos estrangeirismos veio com a comparação entre as tabelas 1 e 2 , de um lado, e a tabela 3, de outro. Os falantes mais novos que acessam a internet diariamente em 
casa demonstraram já usar de forma consciente a maioria das palavras da lista oferecida, como podemos confirmar na tabela a seguir:

\begin{tabular}{|l|l|l|}
\hline \multicolumn{3}{|c|}{ Falantes adolescentes que acessam internet em casa } \\
\hline & Descrição compatível & Aplicação na frase \\
\hline Download & $100 \%$ & $100 \%$ \\
\hline Link & $80 \%$ & $80 \%$ \\
\hline Web & $80 \%$ & $80 \%$ \\
\hline Home & $80 \%$ & $80 \%$ \\
\hline Homepage & $80 \%$ & $80 \%$ \\
\hline Scrap & $50 \%$ & $50 \%$ \\
\hline Scrapbook & $50 \%$ & $50 \%$ \\
\hline Bug & $50 \%$ & $50 \%$ \\
\hline Spam & $30 \%$ & $30 \%$ \\
\hline Send & $0 \%$ & $0 \%$ \\
\hline Print & $100 \%$ & $100 \%$ \\
\hline Password & $100 \%$ & $100 \%$ \\
\hline Profile & $0 \%$ & $50 \%$ \\
\hline Log in & $75 \%$ & $75 \%$ \\
\hline e-mail & $100 \%$ & $100 \%$ \\
\hline Site & $100 \%$ & $100 \%$ \\
\hline Messenger & $100 \%$ & $100 \%$ \\
\hline Network & $0 \%$ & $0 \%$ \\
\hline Pop up & $100 \%$ & $100 \%$ \\
\hline & &
\end{tabular}

A última tabela, que apresenta dados coletados com o grupo de falantes de até $\mathrm{X}$ anos que frequentam lan houses traz resultados semelhantes aos da tabela anterior, compondo o painel contrastante do ponto de vista etário:

\begin{tabular}{|l|l|l|}
\hline \multicolumn{3}{|c|}{ Falantes adolescentes que frequentam lan houses } \\
\hline & Descrição compatível & Aplicação na frase \\
\hline Download & $100 \%$ & $100 \%$ \\
\hline Link & $90 \%$ & $100 \%$ \\
\hline Web & $80 \%$ & $80 \%$ \\
\hline Home & $100 \%$ & $100 \%$ \\
\hline Homepage & $100 \%$ & $100 \%$ \\
\hline Scrap & $50 \%$ & $50 \%$ \\
\hline Scrapbook & $50 \%$ & $50 \%$ \\
\hline Bug & $100 \%$ & $100 \%$ \\
\hline Spam & $30 \%$ & $30 \%$ \\
\hline Send & $30 \%$ & $70 \%$ \\
\hline Print & $100 \%$ & $100 \%$ \\
\hline Password & $100 \%$ & $100 \%$ \\
\hline Profile & $0 \%$ & $50 \%$ \\
\hline Log in & $100 \%$ & $100 \%$ \\
\hline
\end{tabular}




\begin{tabular}{|l|l|l|}
\hline e-mail & $100 \%$ & $100 \%$ \\
\hline Site & $100 \%$ & $100 \%$ \\
\hline Messenger & $100 \%$ & $100 \%$ \\
\hline Network & $10 \%$ & $10 \%$ \\
\hline Pop up & $80 \%$ & $80 \%$ \\
\hline
\end{tabular}

\section{Print desse momento!}

Dois dos cinco falantes pertencentes ao grupo, ambos do sexo feminino, quando perguntados se a lista havia deixado de trazer alguma palavra em Inglês conhecida através da internet, responderam nomes de programas, como lime wire. Quando perguntadas sobre a possibilidade de alguma daquelas palavras ser utilizada fora do contexto virtual, ambas responderam que sim, mas apenas pelo grupo de amigas em comum às duas (todas adeptas do uso de lan houses). Vejamos trechos do depoimento de uma dessas falantes:

\begin{tabular}{|l|l|}
\hline Jhonatta & $\begin{array}{l}\text { Então, alguma dessas palavras da lista é utilizada por } \\
\text { você sem ser para coisas da internet? }\end{array}$ \\
\hline Falante T & $\begin{array}{l}\text { (risos) então.. então, né (risos) a gente usa print, por } \\
\text { exemplo, tipo um congelamento assim, sabe? (risos) }\end{array}$ \\
\hline Jhonatta & Como assim, congelamento? \\
\hline Falante T & $\begin{array}{l}\text { Ai, to sem graça, fessor... (risos) lembra o dia que o } \\
\text { senhor falou "os alunos foram tudo embora"? (risos) } \\
\text { Daí a gente falou "pára tudo, print desse momento", o } \\
\text { senhor deve ta lembrado. [ a aluna faz um gesto se- } \\
\text { melhante ao de uma scanner captando imagens] }\end{array}$ \\
\hline Jhonatta & Verdade, mas explica esse gesto que vocÊs fizeram \\
\hline Falante T & É imitando o programa, o congelamento da imagem. \\
\hline Jhonatta & Ah, sim, e isso é bem usado, né? \\
\hline Falante T & $\begin{array}{l}\text { A gente usa direto, fessor, não sei se todo mundo u- } \\
\text { sa... na escola e na lan a gente usa direto }\end{array}$ \\
\hline
\end{tabular}

No fragmento acima, a entrevistada, de 14 anos de idade, constata o uso de uma das expressões inicialmente utilizadas para nomear um ato estritamente ligado ao uso de informática como uma expressão comum em sua comunidade de prática. Em situação diferente, outro entrevistado define "site" de forma que nos proporciona ratificar esse termo como vocábulo da língua portuguesa, embora apresente ainda grafia não correspondente ao nosso idioma. Vejamos: 


\section{FACULDADE dE FoRMAÇÃo de PROFESSORES}

\begin{tabular}{|l|l|}
\hline Jhonatta & Site: \\
\hline Falante R & $\begin{array}{l}\text { Site? Site é o site, né? É, cara, o site, não sei dizer de } \\
\text { outra forma, é o site, tipo o lugar onde estão as in- } \\
\text { formações, a página }\end{array}$ \\
\hline Jhonatta & $\begin{array}{l}\text { E se eu disser essa frase: O site é tão grande que a } \\
\text { gente se perde nele. }\end{array}$ \\
\hline Falante R & $\begin{array}{l}\text { Tamanho do site, tamanho da página, tem várias coi- } \\
\text { sas pra fazer, muitos lugares e pode se perder, sei lá }\end{array}$ \\
\hline
\end{tabular}

Nesse trecho, percebe-se que, mesmo sem ter conhecimento do Inglês, o uso constante da palavra "site" já aferiu ao falante o significado de lugar para essa palavra. Ao responder a pergunta sobre como definir o vocábulo, o falante se mostra tão familiarizado com o termo que o repete várias vezes, afirmando implicitamente que não há outra forma melhor para definir site. Em outro trecho da entrevista, pergunto se ele acharia a forma "sítio" mais apropriada e ele me responde com uma torrente de risos. Repare que, quando a palavra é inserida no contexto, o falante comenta sobre a dimensão territorial do site, o que reafirma seu conhecimento pleno do significado e do uso desse vocábulo em Português.

\section{Algumas descobertas}

Os dados coletados a partir das palavras oferecidas aos entrevistados foram importantes para que comprovássemos a variação etária existente no processo de absorção dos anglicismos oriundos da internet. Já era esperado que, de fato, o público mais jovem reagisse de forma mais receptiva em relação a esses termos, já que necessitam usá-los todos os dias. Os mais velhos, geralmente, não possuem o hábito de utilizar a internet como entretenimento e, mesmo os que o fazem, ainda não assimilaram o contato com o mundo virtual como algo que faz parte de sua vida. Se, por um lado, temos uma geração que nasceu de frente para as telas de computadores, por outro lado, temos uma geração que viveu e alcançou a maturidade sem ter o mínimo contato com essas máquinas.

As descobertas mais interessantes, no entanto, vieram daquilo que não foi programado para as entrevistas. Os falantes frequentadores de lan houses, ao serem perguntados sobre alguma palavra que, por ventura, a lista não houvesse contemplado, forneceram informações muito relevantes quanto a vocabulários desconhecidos até 
mesmo pelo entrevistador. É o caso de palavras como "leg", "bugar", "lol" "nick" e "goglar". Vejamos o que nos dizem os dados acerca dessas novas formas:

\begin{tabular}{|l|l|}
\hline Jhonatta & $\begin{array}{l}\text { Tem alguma palavra que você acha que faltou na } \\
\text { lista de termos da internet? }\end{array}$ \\
\hline Falante R & $\begin{array}{l}\text { Na lista, acho que faltou leg, lol, nick... Leg e lol } \\
\text { são para dizer que a parada tá devagar, serve até pa- } \\
\text { ra falar de alguém. Nick é nosso nome na lan. }\end{array}$ \\
\hline
\end{tabular}

\begin{tabular}{|l|l|}
\hline Jhonatta & $\begin{array}{l}\text { Tem alguma palavra que você acha que faltou na } \\
\text { lista de termos da internet? }\end{array}$ \\
\hline Falante C & $\begin{array}{l}\text { Faltou palavra na lista sim... Bugar, que é quando } \\
\text { fica dando problema no pc, mas se bem que você } \\
\text { botou bug, né? Mas a gente usa mais bugar }\end{array}$ \\
\hline & $\begin{array}{l}\text { Faltou também leg, essa a gente usa mesmo fora da } \\
\text { net, tipo, tá leg hoje? Quando vamos dizer se o cara } \\
\text { tá meio lerdo, entendeu? }\end{array}$ \\
\hline
\end{tabular}

\section{O computador está bugando}

Com o fim do século XX, muito se especulou sobre o que poderia ocorrer com a rede mundial de computadores. Isso se deveu ao fato de que os cientistas da área de micro computação temiam a existência de um algoritmo falho, que não permitiria que as máquinas fizessem a correta passagem do ano de 1999 para o ano de 2000. Especulava-se, na verdade, que o mundo virtual retornaria ao ano de 1900 ao invés de passar para o século seguinte. Isso ocorreria por conta da falha do sistema, que não havia sido programado para atingir o novo século. As ocorrências poderiam ser catastróficas para a economia mundial, pois os bancos talvez perdessem todos os dados armazenados, até mesmo deixando de existir. $\mathrm{O}$ ano de 2000 chegou e nossa primeira década do século XXI está quase no fim. Nada de mais aconteceu. E esse episódio curioso ficou conhecido como o "bug" do milênio.

Nessa época, a internet ainda não havia alcançado o raio de aceitação social que possui hoje, embora já fosse uma ferramenta bastante recorrente para a comunicação a longa distância e para o acesso ao conhecimento. Nas lan houses da época, muito se falava sobre o acontecimento, o que acabou familiarizando os frequentadores desses lugares com o termo. Com o passar de alguns anos, todo 
tipo de travamento que ocorria nos computadores passou a ser chamado de bug, inclusive aqueles que são causados por vírus. No Inglês, a palavra bug se traduz como micróbio, inseto ou mesmo pequeno bichinho.

Quando perguntados sobre o significado da palavra "bug", alguns dos entrevistados demonstraram certa dificuldade em produzir uma resposta mais exata. Muitos deles só conseguiram se lembrar da forma "bug" depois da inserção do contexto frasal. Entretanto, como mostra o trecho acima transcrito da entrevista do falante $\mathrm{C}$, a forma bugar é conhecida por todos nas lan houses. $\mathrm{O}$ verbo exprime a ação falha do computador, que pode estar travando em consequência de algum programa prejudicial ou mesmo de algum vírus. A recorrência à forma bug, inicialmente, era tão forte, que em algum tempo foi necessário que esses falantes criassem uma palavra em sua própria língua, com as regras flexionais do Português, para expressar a ação que a todo instante os atrapalhava. Nesse momento, nasce essa forma verbal, mostrando que a tendência fatídica de uma expressão incorporada de outro idioma é se consolidar mediante o uso recorrente na língua que a abarcou. $\mathrm{O}$ mesmo acontece com printar e goglar.

\section{O que é estar "leg"?}

Nas entrevistas feitas com os falantes $\mathrm{C}$ e R, já mencionados anteriormente, surge mais um termo desconhecido entre os dados da pesquisa: "leg" seria usado como gíria do cotidiano, como algo sinônimo ao adjetivo "lerdo". Ambos confirmam a mesma origem para o termo: são assíduos usuários do jogo Counter Strike, sucesso nas lan houses de todo o mundo.

Ocorre que, quando acontece algum tipo de travamento do mecanismo que gere o jogo, a expressão que aparece para avisar sobre o problema é exatamente LEG. E a absorção para o vocabulário dos meninos praticantes do jogo já se evidencia. O falante $\mathrm{M}$, de 11 anos de idade, confirma a adoção do termo no trecho transcrito abaixo:

\begin{tabular}{|l|l|}
\hline Jhonatta & Você conhece a palavra leg? \\
\hline Falante M & $\begin{array}{l}\text { É do CS, né? É, do jogo CS. É quando o jogo buga, } \\
\text { quando fica lento de mais. Pode ser o cara também, } \\
\text { que fica leg, tipo, leg, lentão, entendeu? }\end{array}$ \\
\hline
\end{tabular}

10. Considerações finais: algumas constatações 
O trabalho ora apresentado traz dados que nos levam a refletir sobre a natureza dos estrangeirismos e sua importância dentro da identidade de um grupo. Em primeiro lugar, esclarece-se que a aceitação dos termos de origem estrangeira está extremamente vinculada ao uso desses termos pela comunidade. Quando fica constatado que os mais jovens conhecem mais os termos em Inglês advindos da internet, reafirma-se apenas o que já se sabia: que os mais velhos desconhecem os termos por, em geral, terem menos contato com o universo virtual.

As lan houses, enquanto comunidades de prática, ratificam a ideia de que um termo de outra língua é aceito ou refutado num processo de acordo tácito feito entre aqueles cujas práticas sociais apresentam a necessidade de se defrontar diante dessas aparições. As formas originárias do Inglês que já recebem tratamento gramatical do português constituem prova cabal da incorporação dos estrangeirismos como fenômeno linguístico que não se pode deter (e que, em verdade, não se deve deter).

Admitimos ainda que a presente pesquisa esteja longe de trazer uma verdade completa sobre o assunto. Na verdade, o que se pretendeu foi apresentar provas de que o processo natural de adoção dos estrangeirismos por falantes que, de fato, utilizam com frequência esses termos não deve ser analisado como prejuízo à cultura ou a língua, mas como algo próprio da fala na sociedade. 


\section{FACULDADE de FoRMAÇÃO de PROFESSORES}

\section{BIBLIOGRAFIA}

ARCARI, Viviane Deluchi \& COLAÇO, Silvania Faccin. Os estrangeirismos na linguagem do cotidiano, 2004, Santa Maria. Anais do I Seminário Nacional de Filosofia e Educação, 2004.

BAGNO, Marcos. Português ou brasileiro? Um convite à pesquisa. São Paulo: Parábola, 2001.

BAGNO, Marcos. Preconceito linguístico. O que é, como se faz. 3. ed. São Paulo: Loyola, 2000.

FARACO, Carlos Alberto e outros. Estrangeirismos: Guerras em torno da língua. São Paulo: Parábola, 2001.

Garcez, P. M.; Zilles, Ana Maria Stahl. Estrangeirismos: empréstimo ou ameaça. In: Silva, Fábio Lopes da; Moura, Heronides Maurílio de Melo. (Org.). O direito à fala: a questão do preconceito linguístico. Florianópolis: Insular, 2001, p. 39-52.)

JUNG, Neiva Maria; Garcez, P. M. Além do repertório linguístico: aspectos simbólicos diversos na construção da identidade étnicolinguística alemã na escola de comunidade rural multilíngue. In: Cavalcanti, Marilda do C.; Bortoni-Ricardo, Stella Maris. (Org.). Transculturalidade, linguagem e educação. Campinas: Mercado de Letras, 2007. p. 97-122.

ZILLES, A. M. S.; GARCEZ, P. M. Estrangeirismos: desejos e ameaças. In: FARACO, Carlos A.. (Org.). Estrangeirismos: guerras em torno da língua. São Paulo: Parábola, 2001. p. 15-36. 